\title{
Introduction: African Industrial Development, Values and Health Care
}

\author{
Maureen Mackintosh, Geoffrey Banda, Paula Tibandebage \\ and Watu Wamae
}

This is a book about the industrial development of pharmaceutical production in Sub-Saharan Africa. Yet the values that drive this industrial enquiry are rooted in the needs of a subcontinent with the worst health status in the world. The central argument of this book is that industrial development in pharmaceuticals and the capabilities it generates are necessary elements in African initiatives to tackle these acute health care needs. A successful pharmaceutical industry is no guarantor of good health care: India indeed has managed to grow a highly successful industry while leaving many of its people without access to competent care. However, without the technological, industrial, intellectual, organizational and research-related capabilities associated with competent pharmaceutical production, the African subcontinent cannot generate the resources to tackle the needs and demands of its population.

The book is a collective endeavour, by a group of editors and authors with a strong African and more broadly Southern presence, to find ways forward that link technological development, investment and industrial growth in pharmaceuticals to improving access to essential good-quality medicines, as part of moving towards universal access to competent health care. This book presents original research, much of it from recent fieldwork in African contexts. The authors include academics, researchers and practitioners, including some who have been or are currently managing pharmaceutical firms in African contexts, and some deeply involved in policy formulation and implementation. We aim to 
shift the emphasis in international debate towards much more attention to the scope for sustained Africa-based and African-led initiatives to tackle this huge challenge.

In this we are contributing to a shift in mind-set that is already under way. African governments are increasingly considering medicines supply as a national security issue. African Heads of States have adopted the African Union's Pharmaceutical Manufacturing Plan for Africa (African Union, 2007), and regional African bodies are taking similar initiatives. There has also been a sharp shift in approach amongst UN agencies, including WHO and UNAIDS, from earlier critical stances towards support for the development of health sector manufacturing of medicines and supplies in Africa (Sidibé et al., 2014). That shift in turn has built on work by UNIDO with African governments and the African Union (e.g. African Union 2012a ${ }^{1}$; UNIDO, 2010; UNIDO/GoT, 2012). Bilateral donors, notably German and Japanese, are actively supporting upgrading in health-related industries.

The book's roots are in historical political economy. The process of building - or failing to build - industrial strengths and industry-health system synergies is long term, as the complex 30-year trajectory of Brazil's health-industrial complex illustrates. The book starts by challenging a highly persistent international myth: that Sub-Saharan Africa has no pharmaceutical industry. On the contrary, the industry has a long history and is strongly embedded in a number of African countries. Operating in a relatively high-skill, high-technology sector, pharmaceutical firms have faced all the well-known challenges of African countries' infrastructural weakness, in skills, utilities and transport, but many have built successful businesses and are investing in technological and product upgrading. Regional inter-country trade is expanding, and new investment opportunities are opening up.

\section{The big challenges are twofold}

First, there is the fight to sustain this industrialization effort in the current global market context - which is much more constraining to new competitors than the market context facing, for example, India in the years when it was building its pharmaceutical success story. Multilateral and bilateral policies have reinforced the stringent competition faced by Africa-based medicines producers. A core concept in our analysis is industrial capabilities. In Part I we explore the sources of the organizational, institutional, technical and human capabilities to make good products, to compete profitably in globalized markets that constantly 
force firms to upgrade, to overcome barriers to market entry and to distribute products effectively.

The second challenge is to ensure that the skills and competence built up by the manufacturers and distributors actually feed into better health care access for African populations. The institutional capabilities of the health system need also to be built up, to support, buy and use effectively locally manufactured supplies. Only on that basis can governments generate policies that bring the interests of the industrial and health sectors closer together, to collaborate for mutual benefit. In Part II we examine some country experiences of health-industry interactions, comparing East African countries' experience with Brazil and India, arguing that health system structure and initiative are as important as industrial policy to successful linkage. The values that underpin the importance of the pharmaceutical sector, its claim to policy priority, are rooted in the ethical requirement of universal access to competent health care.

The chapters in Part III therefore tease out experiences of some of the key aspects of health-industry interactions in more detail and identify some important policy issues to be tackled. All these issues are framed by political economy considerations of the ethics, interests and institutions involved. They include the highly contentious matters of price controls and standard setting for pharmaceutical products, plus examination of sources and problems of financing, the scope for innovative procurement processes that can reflect health system values while providing incentives for industrial investment, and the contested but important role of industrial manufacturers' associations and political lobbying.

This book is a loud challenge to pessimism about African industrial development and health care commitment. African governments have responsibility for their populations' health needs, and cannot address them without industrial expertise. The book explores the conditions under which industrial improvement can benefit those who need access to medicines and health care, pulling together the arguments for access and distribution with those for investment and industrial development. There are different routes by which improving supply capacities can generate local health improvement: this book is about how to generate local paths that work. It also identifies ways in which international donors and policy makers can shift from impeding to supporting the long-term development of local industrial and health system capabilities in African countries. 
4 Mackintosh, Banda, Tibandebage and Wamae

\section{Note}

1. See also http://www.local-pharma-production.net/index.php?id=97.

(c) (i) Except where otherwise noted, this work is licensed under a a copy of this license, visit https://creativecommons.org/version4 